\title{
Emotion, Fear and Superstition in the New Zealand Stockmarket ${ }^{*}$
}

\author{
Glenn Boyle \\ Andrew Hagan \\ R. Seini O'Connor
}

Nick Whitwell

11 June 2004

\footnotetext{
Boyle is executive director of the NZ Institute for the Study of Competition and Regulation, Victoria University of Wellington; Hagan is a postgraduate student at Otago University; O'Connor is a research officer at Castalia; Whitwell is a credit manager for National Australia Bank. Work on this paper began while all authors were at Otago University. For helpful comments, we are grateful to John Howells, Vivien Pullar, an anonymous NZEP referee, and participants at the 2003 New Zealand Finance Colloquium. Peter Grundy provided valuable research assistance. Any remaing errors or ambiguities are our responsibility.

Contact author: Glenn Boyle, NZ Institute for the Study of Competition and Regulation, PO Box 600, Wellington, New Zealand; glenn.boyle@vuw.ac.nz.
} 


\begin{abstract}
We analyse the reaction of the New Zealand stock market to five economicallyneutral events that psychology research indicates have varying degrees of influence on emotion and mood. Contrary to behavioural finance principles, only one of these events is associated with mean or median returns that are statistically different from those on non-event days, and even this disappears in the post-1984 period. However, several events offer returns that differ from those on non-event days in an economically significant manner. Moreover, the variance of returns for event days is typically much greater than the variance for non-event days. Contrary to what theory would suggest, the market's propensity to react to economically-neutral events is largely independent of the mid-1980's market reforms.
\end{abstract}

JEL Classification: G10; G314; A12 


\section{Emotion, Fear and Superstition in the New Zealand Stockmarket}

\section{Introduction}

A central paradigm of financial economics is the efficient markets hypothesis. This asserts that securities prices do not systematically deviate from those that can be justified by economic fundamentals; any divergence between price and fundamental value provides an opportunity for profitable trading, thereby ensuring that the deviation is transitory. Given the importance of the efficient markets hypothesis to economists' understanding of financial markets, it is unsurprising that a large amount of research effort has been devoted to the analysis of anomalies - aspects of asset price behaviour that appear to conflict with market efficiency. Among the more celebrated anomalies are high equity premia, excess stock price volatility, mean reversion and predictability, size effects, and return seasonalities, to name but a few.

However, interpretation of these anomalies is by no means straightforward. If the asset pricing models used to benchmark actual price and return behaviour against the efficient markets ideal are mis-specified, then any real world deviations from the behaviour implied by these models may be due to model failure rather than to any violation of market efficiency. According to this view, anomalies simply reflect researchers' inability (thus far) to build a rational asset pricing model that correctly captures the risk-return trade-off. Subsequent work provides some support for this view, as more complex pricing models suggest that many of the above anomalies may not, after all, be all that anomalous. For example, excess volatility is consistent with rational time-varying expected returns, high equity premia with habit formation or concentrated risks, the January effect with tax-loss selling, and so on.

More recent efforts to uncover anomalies have focussed on phenomena that cannot be so easily rationalised. Rather than compare actual price behaviour with some model of efficient markets prices, this approach has concentrated on identifying exogenous economically-neutral events that psychology research has shown may have a causative effect on investor behaviour. Because such events are, by definition, independent of economic fundamentals, they cannot have a systematic effect on stock prices in an efficient market. 
However, if markets are inefficient, and thus subject to behavioural and psychological influences, then these events may affect prices by inducing irrational impulses in investor behaviour. As Saunders (1994) points out, the implied causality running from the economically-neutral event to market prices means that the existence of any systematic price effects cannot be attributed to the use of an incorrectly-specified asset pricing model and thus pose a significant challenge to the efficient markets hypothesis.

Early studies of psychological biases (or behavioural effects, as they are more commonly known in financial economics) in securities prices primarily focus on a single economically-neutral event using United States (US) data (e.g., Kolb and Rodriguez, 1987; Ariel, 1990; Saunders, 1993), an approach which raises concerns about accidental datamining. Consequently, subsequent research has examined single events using either a different time series of US data (e.g., Brockman and Michayluk, 1998; Hirshleifer and Shumway, 2003) or data from other countries (e.g., Cadsby and Ratner, 1992; Lucey, 2000; Hirshleifer and Shumway, 2003; Yuan et al , 2001).

One problem with these studies is that the same statistical model is applied to all countries, thereby ignoring differences in market structure, customs and culture. As a result, cross-country differences in market reaction to a given event are difficult to interpret. Similarly, the focus on a single event makes it difficult to properly evaluate the underlying behavouralist argument. For example, an observed association between price movements and the occurrence of an economically-neutral event known to have strong psychological effects is, on the face of it, consistent with the behaviouralist view. But if the same dataset also uncovers a similar association between price movements and the occurrence of another economically-neutral event known to have only weak or non-existent psychological effects, then the behaviouralist view looks less secure. Single-event studies do not permit such comparisons.

In this paper, we analyse the market reaction to several economically-neutral events in a single country (New Zealand). This alternative approach has a number of advantages. First, in contrast to single-event studies, the use of a common dataset across different events permits comparison of the market reaction to events that differ in their behavioural 
implications and thus provides insight into the relative significance of different psychological biases. Second, US markets generally have greater depth, liquidity and transparency than other markets. If the observed relationships between returns and economically-neutral events in US markets are due to psychological biases, then similar relationships should be at least as apparent in the smaller New Zealand (NZ) market where the scope for such inefficiencies is greater. On the other hand, failure to detect similar relationships in NZ data would strengthen the view that the US results reflect accidental data-mining. Thus, NZ data provide an important check on the US results. Third, and similarly, the multi-country studies noted above generally report considerable variation in their results across countries, but have little to say about the possible causes of this phenomenon. One obvious potential cause is the extent of a market's "liberalisation". Since NZ's financial sector was subject to considerable liberalisation in just a few months during 1984 and 1985, data from that country provide an ideal laboratory for testing the hypothesis that the reaction of financial markets to economically-neutral events is sensitive to the extent of market liberalisation. Fourth, previous studies pay scant attention to the psychological underpinnings of the events they analyse, or the mechanisms by which these may influence securities prices, omissions we attempt to rectify. Finally, most other studies do not analyse NZ data, so our study adds to the body of knowledge concerning the extent of financial market anomalies and provides further evidence on NZ market efficiency. ${ }^{1}$

In the remainder of this paper, we analyse the market reaction to five economicallyneutral events: (i) daylight saving time changes, (ii) pre-holidays, (iii) Melbourne Cup day, (iv) lunar phases, (v) Friday the 13th. Psychology research indicates that these events have effects on emotion and mood that range from the primarily physiological (daylight savings changes) to the fundamentally superstitious (Friday the 13th). In the next section, we briefly outline the psychology arguments and evidence relating to each event, and consider the implications of these for financial markets. Section 3 contains our results and accompanying discussion while section 4 offers some concluding remarks.

$1 \quad$ Exceptions are Agrawal and Tandon (1994) who use NZ data from 1971 to 1987, and Yuan et al (2001) who employ 1988-2001 data. Our data series is considerably longer than either of these. Moreover, unlike these two studies, it contains data in roughly equal quantities from the pre- and post-deregulation periods. 


\section{Psychological biases and economically-neutral events}

A common feature of so-called economically-neutral events is that each is claimed, or assumed, to affect investor behaviour via changes in mood and emotion. The effects of mood on decision-making processes have been well documented and indicate that it may be a significant influential factor on cognition (e.g., Isen, 1989). Good moods are generally associated with more optimistic judgements and choices, and evoke heuristic styles of information processing (e.g., Schwarz and Bless, 1991). As noted by Forgas (1989), good moods also tend to lead to faster and more efficient decision making than do negative moods. By contrast, the presence of intense mood states, particularly sadness, has been found to interfere with task performance by increasing the frequency of task-irrelevant, mood-related thoughts (see Kitzan, 2001). Moreover, Johnson and Tversky (1983) find that negative mood can critically alter judgements of risk.

Asset prices have two fundamental components: the future cashflows expected by the market and the discount rates, or expected returns, the market uses to price these cashflows. These components reflect investor consensus about, respectively, the location of the future cashflow distributions and the risk of the cashflows. Consequently, mood changes following economically-neutral events can potentially affect asset prices in two main ways. First, excessive optimism or pessimism may induce bias in investor expectations about future cashflows. Second, investors may over- or under-weight the risk associated with future cashflows.

\subsection{Daylight saving time changes}

Daylight Savings is vernacular terminology used in New Zealand to indicate the onset or ending of Daylight Time, a clock setting that is one hour in advance of New Zealand Standard Time. Daylight Time is observed over the summer months from October of one calendar year to March of the next. Although first introduced in a reduced form in 1929 (the clock adjustment then was only 30 minutes), the current daylight time system was introduced in the Time Act of 1974. Since then, the observance period has increased twice following 
governmental surveys of energy consumption and public approval. The current observance period is set in the Daylight Time Order of 1990, commencing at 2.00am Standard Time on the first Sunday in October each year and ceasing at 2.00am Standard Time on the third Sunday in March the following year.

Although the time change involved in moving to and from Daylight Time is slight, it may have significant physical effects on individuals adjusting to the new clock setting. Numerous studies (e.g., Monk and Alpin, 1980) have noted the effects on the human body of sleep deprivation and desychronisation of the "internal clock", which commonly occur as a result of shift work and travel across time zones. Similarly, behavioural and physiological changes that have been observed following daylight time changes include disruption in waking time for up to five days following the shift (Monk and Alpin), a marked change in the classroom behaviour of children (Hicks et al , 1980), and a significant increase in the number of traffic accidents for the following week (Hicks et al , 1983). More generally, Folkard et al (1976) find that changes in sleep schedules can result in changes in performance levels, especially in tasks with a high cognitive load. Significantly, Taub and Berger (1976, p30) conclude that "...alterations in a customary sleep-wakefulness pattern may be more closely associated with the efficiency of human performance than total sleep duration or time spent in certain sleep stages." This suggests that the effects of daylight time changes may be more than just a matter of the gain or loss of an hour's sleep. Changing the clocks by even an hour may have a significant physical and psychological effect.

Despite these significant implications for mood, efficiency, and general feelings of well-being, there has been little research into the possible effects of daylight time changes on financial market behaviour. One exception is Kamstra et al (2000) who find that Monday returns following time changes are much more negative than on regular Mondays in the US, Canada and the United Kingdom, but not in Germany. They suggest that this effect may be due to sleep desynchronosis that causes greater anxiety and hence less risk-taking behaviour in market participants. The findings of Folkard et al (1976) and Taub and Berger (1976) noted above imply a related, but alternative, explanation: sleep desynchronosis leads to an 
increased rate of human error due to the disruption of normal performance-related biological rhythms.

\subsection{Pre-holiday periods}

Psychological research into mood changes prior to holiday periods has been limited, but several studies have indicated that the arrival of a short holiday such as a weekend has a positive effect. For example, in a longitudinal study on a group of female employees, Rossi and Rossi (1977) find that positive moods peak at weekends; an analogous investigation by Christie and Venables (1973) into male mood cycles finds that 'euphoria' scores are lowest on Monday mornings and highest on Friday evenings. Nevertheless, Miller (1959) stresses that pre-holiday periods need not be associated with mood upswings if the holiday itself involves some potentially stressful event. Consistent with this view, Persson and Sjöberg (1985) report that an overseas trip is typically precipitated by a downturn in mood. Similarly, Kossof (1992) reports an increase in depression during the Christmas period.

Interestingly, the effect of impending holidays on financial market behaviour has been subject to considerable analysis. Consistent with the view that pre-holiday periods are associated with greater optimism about future investment prospects, Ariel (1990) finds that mean US market returns between 1963 and 1982 are significantly higher on the day before a holiday than on other days. Pettengill (1989) shows that this difference holds independently of firm size, although it is larger for small firms, while Brockman and Michayluk (1998) confirm its existence in more recent data. Using 1962-87 data from 11 countries, Cadsby and Ratner (1992) report higher pre-holiday returns in some countries, but not in others, and suggest that this is due to country-specific differences in institutions and practices.

\subsection{Melbourne Cup day}

Run on the first Tuesday of each November, Australia's premier race day is not a holiday in NZ, but the strong media attention and carnival atmosphere surrounding this event may induce a general feeling of well-being. Although not previously subject to any formal analysis, anecdotal evidence suggests that at least some financial market participants believe 
that Melbourne Cup day is associated with heightened investor optimism. Consider, for example, this assessment by the spokesman for a major NZ brokerage house:

"Melbourne Cup days always seem to be a bit bullish for some reason."

Otago Daily Times, 7 November 2001.

According to this view, Melbourne Cup days are associated with higher returns. Since the advent of Melbourne Cup day cannot have any systematic effect on economic fundamentals, any such relationship with stock market returns is consistent with the existence of behavioural effects.

\subsection{Lunar phases}

Belief in lunar effects appears to stretch back to ancient times (see Laycock, 1843) and can be linked to Assyrian and Babylonian mythology, which views human fertility as dependent on the moon cycle. Certainly, in pre-medical times, the correlation between the lunar and the menstrual cycle may have been construed as causal; but given greater knowledge of hormonal processes and the variation in cycle length between women, there seems no reason to suppose that the former cycle affects the latter in any way. However, the moon's alleged effects are not limited to fertility - the more common association is with madness, from which has arisen the term 'lunacy', derived from luna, the Latin term for moon.

The prevalence of the belief in a lunar-lunacy link has created much interest in the possibility of correlation between psychological state and the lunar cycle. For example, Templer et al (1982) find a significant correlation between lunar phase and accident injuries during darkness hours, a finding they attribute to the luminosity characteristics of the moon in its various phases. However, as Rotton and Kelly (1985) point out, the moon is a relatively minor source of light, so human behaviour would be much more erratic if it were affected by light levels this insignificant. In a similar study, Lieber and Sherin (1972) discover a statistically significant correlation between lunar periodicity and homicides committed in a 
Florida county over a 15-year period. They contend that this result can be explained by reference to the gravitational pull of the moon which they suggest can cause "...cyclic changes in water flowing among the fluid compartments of the body (intracellular, extracellular, intravascular and intraluminal), as well as changes in total body water, resulting in what might be termed 'biological tides' " (p. 69). These tides, they suggest, act along with their associated electrolytic and hormonal shifts to cause psychological disturbances. However, such effects have gone undocumented in the medical literature and are therefore likely to be slight at best. Furthermore, there is no reason to believe that "biological tides" do in fact exist in accordance with the phases of the moon: although the moon may influence the tides of the earth's ocean, this water is free, not bounded as it is in the body. Furthermore, the ocean's tides are affected by the moon's distance from the earth (which has a 27-day cycle) and not its phase (which has a 29.5-day cycle). Thus, both the Templer et al and Lieber and Sherin correlations may simply be chance occurrences.

Overall, as Rotton and Kelly (1985) note, there is little evidence for a significant relationship between lunar phases and extreme individual behaviour. Studies which fail to find any lunar effect include comparisons of crisis calls (Byrnes and Kelly, 1992), attempted suicides (Mathew et al , 1991; Rogers et al , 1991), psychiatric patient "acting-out" behaviour (Durm et al, 1986), and traffic accidents (Alonso, 1993). Moreover, where such a relationship does exist, it is unlikely to be mediated by physical variables, more probably reflecting simple superstition and the self-fulfilling prophecy - the very act of believing that the moon alters one's behaviour may result in the unconscious altering of behaviour, or increased attention being paid to unusual behaviour in others. Some support for the superstition mechanism is provided by Agus (1973) who finds that psychiatric nurses believing in lunar influence have an increased likelihood of recording unusual behaviours in their patients. In addition, as noted by Sands and Miller (1991), superstition is consistent with prevalence of the full moon (as opposed to other lunar phases) in mythology and folk psychological explanations - when full, the moon is at its most salient, and thus more likely to be used as a focus for causal attribution. 
Whether driven by the effects of superstition on mood or by some other factor, two recent studies claim evidence for a lunar influence on financial market prices. Using data from various countries over different time periods, Dichev and Janes (2001) and Yuan et al (2001) report lower mean returns in the full moon period. However, although economically quite large, these differences are statistically insignificant for most countries.

\subsection{Friday the 13th}

Belief in the ill-fortune that supposedly accompanies the date of Friday the 13th is widespread across the Western world and has ancient and somewhat uncertain origins. Both the number 13 and Friday have long and separate histories of "bad luck", but it is believed that the two were combined to create an unfortunate date as recently as the beginning of the 20th Century (see Chaundler, 1970). Explanations for the two lines of superstition can be found in Christian literature - Christ was allegedly crucified on a Friday, and the number of people seated at the table for the last supper was 13 . Modern fear of the number 13 is readily apparent, with many buildings lacking a thirteenth floor, street numbers skipping from 11 to 15 (sometimes substituting 13 with 11a) and hospitals even declining to label their operating theatres with the number. Fear of the thirteenth day of any month if it falls on a Friday seems to be popularly spread, with many films marketed around the concept.

Despite this widespread awareness, there is little evidence of behavioural Friday the 13th effects. One exception is Scanlon et al (1993) who find that there is a larger number of traffic accidents in the UK on Friday the 13th, despite there being fewer cars on the roads. The authors do not suggest a cause for this phenomenon, presumably because no obvious one exists; any effects on behaviour are almost certainly mediated by superstition and mental states rather than by physical variables. As with the case of a full moon, any superstitious belief in the negative connotations of Friday the 13th may be reinforced by a combination of increased attention to unusual or negative events occurring on that day and a "self-fulfilling prophecy" effect whereby expected outcomes are unconsciously striven for.

In research that focuses on financial markets, Kolb and Rodriguez (1987) find that mean Friday the 13th returns are significantly lower than the mean returns for all other 
Fridays, but subsequent work by Dyl and Maberly (1988), Agrawal and Tandon (1994), Coutts (1999) and Lucey (2000) reveals the reverse pattern: mean returns on Friday the 13th tend to be higher than those on regular Fridays, although not usually in a significant manner. These contrasting results seem to suggest that a "Friday the 13th effect" may exist in financial markets, but leave open both the direction and cause of this effect.

\section{Analysis}

\subsection{Data}

If NZ investors respond to economically-neutral events and do so in a manner implied by psychology research and/or folklore, then section 2 suggests that returns should be higher before a holiday and on Melbourne Cup day (due to higher expected cashflows or lower riskadjusted discount rates) and lower on Friday the 13th, full moon days, and following daylight savings changes (due to lower expected cashflows or higher risk-adjusted discount rates). To examine these hypotheses, we use daily returns on the NZSE40, a value-weighted capital index of the 40 largest securities by market capitalisation listed on the NZ Stock Exchange, from January 1967 to November $2001 .^{2}$

For the pre-holiday event, we use the holidays at Waitangi Day (6 February), Easter, Anzac Day (25 April), Queen's Birthday (first Monday in June) and Labour Day (fourth Monday in October), but exclude Christmas due to the potential it creates for the Miller (1959) stress effect alluded to in section 2.2. ${ }^{3}$ For each holiday, the pre-holiday period is defined as the last trading day prior to the commencement of the corresponding holiday. Thus, in the case of the Queen's Birthday holiday, for example, the event day return is the return for the preceding Friday. Daylight savings changes always occur on a Sunday, so the

\footnotetext{
2 These data were obtained from Otago University's New Zealand Share Price Database.

3 In cases where Waitangi and Anzac days fall on a weekend, no additional holiday occurs. Moreover, the NZ market did not close on Waitangi day prior to 1974, so we do not categorise those early observations as holidays. In case different holidays have different market effects (e.g., holidays associated with a long weekend versus those that are not), we also examine the market response to each pre-holiday event individually. However, this leads to no new results, so we report only the aggregate pre-holiday findings.
} 
event day return is that for the following trading day. ${ }^{4}$ The event day returns for the full moon, Friday the 13th and the Melbourne Cup are simply the market returns on those dates. ${ }^{5}$

The pre-holiday, daylight savings, Friday the 13th, and Melbourne Cup event days are easily identifiable from historical calendars and NZ Yearbooks. For the full moon event periods, we use the New Zealand Nautical Almanac and Tide Tables, available from the NZ Marine Department. Non-event days are trading days on which none of these events occurs. ${ }^{6}$

\subsection{Principal tests}

Panels A and B of Table 1 report some simple statistics on the differences between event and non-event day returns. Consistent with the existence of predicted behavioural effects, mean returns are higher on the days before holidays and on Melbourne Cup days, but lower after daylight savings changes. However, with the marginal exception of the preholiday period, none of these differences is significant at conventional levels. Contrary to expectations, Friday the 13th and full moons are associated with higher mean returns, but again these are statistically insignificant. Analysis of positive-return days yields similar inconclusive results, except for pre-holidays. On non-event days, the market rises $52 \%$ of the time, but $64 \%$ of days preceding holidays see an increase in the index value, a difference that is significant at the $1 \%$ level.

\section{Table 1}

\section{Comparison of event day returns with returns on all other days: Full sample}

This table compares the distribution of NZSE40 returns on days corresponding to the economically-neutral events listed below with returns on days that contain none of these events. Data are for the period between 1 January 1967 and 30 November 2001. Daylight savings changes occur in March and October of each year since 1974. The pre-holiday event is the last trading day preceding the holidays at Waitangi Day, Easter, Anzac Day, Queen's Birthday and Labour Day. The Melbourne Cup is held on the first Tuesday of each November. The sample consists of 8045 non-event days; the

4 This is usually a Monday, but as these changes occasionally coincide with the Easter or Labour weekends, it sometimes falls on a Tuesday.

5 Of the 434 full moon days in our sample, 146 occur on non-trading days and are thus excluded from our event day sample. For Friday the 13th, the corresponding numbers are 60 and 3. See section 3.3 for an attempt to alleviate this loss of data for the full moon event.

6 As an alternative, for each event we defined non-event days to be all trading days on which that particular event only did not occur. This had no discernible effect on our results. 
number of event days associated with each event appears below. The p-values are calculated as follows: means - t-test; proportions of positive returns - z-test; medians Mann-Whitney U-test.

Panel A
Panel C

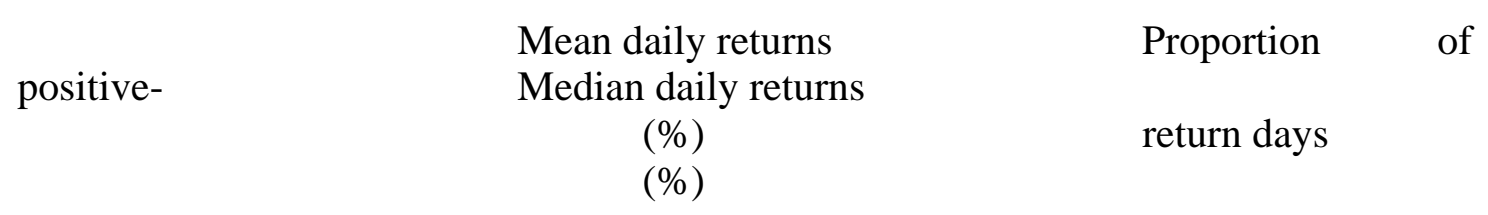

\begin{tabular}{llccccc} 
Event & $\begin{array}{l}\text { Event } \\
\text { Day }\end{array}$ & $\begin{array}{c}\text { Non-Event } \\
\text { Day }\end{array}$ & $\begin{array}{c}\text { Difference } \\
\text { p-value }\end{array}$ & $\begin{array}{c}\text { Event } \\
\text { Day }\end{array}$ & $\begin{array}{c}\text { Non-Event } \\
\text { Day }\end{array}$ & $\begin{array}{c}\text { Difference } \\
\text { p-value }\end{array}$ \\
\cline { 1 - 4 } & & & & & & \\
$\begin{array}{l}\text { Daylight Savings } \\
(\mathrm{n}=55)\end{array}$ & -0.21 & 0.03 & 0.31 & 0.53 & 0.52 & \\
& & & & & & \\
$\begin{array}{l}\text { Pre-Holiday } \\
(\mathrm{n}=123)\end{array}$ & 0.18 & 0.03 & 0.06 & 0.64 & 0.52 & 0.01
\end{tabular}

$\begin{array}{lllllll}\begin{array}{l}\text { Melbourne Cup } \\ (\mathrm{n}=35)\end{array} & 0.10 & 0.03 & 0.70 & 0.60 & 0.52 & 0.36\end{array}$

$\begin{array}{lllllll}\text { Full Moon } & 0.11 & 0.03 & 0.14 & 0.54 & 0.52 & 0.60\end{array}$

$(\mathrm{n}=288)$

$\begin{array}{lllllll}\text { Friday 13th } & 0.04 & 0.03 & 0.92 & 0.51 & 0.52 & 0.84\end{array}$

$(\mathrm{n}=57)$

Although the differences in mean returns are statistically insignificant, they are economically large. For example, assuming a 250-day trading year and ignoring dividends, the mean return on pre-holidays exceeds $50 \%$ per annum, as opposed to the $7 \%$ on offer on non-event days. Or to put it another way, an investor who placed \$100 in the NZSE40 on 23 March 1967 (the day preceding the first holiday in our sample), sold out at the end of that day, placed the proceeds under his bed, and re-invested only on subsequent pre-holidays, would at the end of our sample period have accumulated a sum greater than one-third of that 
achieved by an investor who stayed in the market throughout, despite having been invested

$$
\text { for only } 1.5 \% \text { as long. }{ }^{7}
$$

One interpretation of this evidence is that behavioural effects exist in the NZ stockmarket, but are obscured by the high volatility in daily stock return data. For example, the mean return on days following daylight savings changes is $-0.21 \%$, well below the $0.03 \%$ mean return for non-event days, but the volatility of these returns are such that almost 90 years of data would be needed for this difference to be statistically significant at the $5 \%$ level.

To consider this idea further, we examine the effect of financial liberalisation on event day returns. In a tightly regulated market, daily prices tend to be less volatile, so the problem outlined in the previous paragraph is weakened. Moreover, the incentives that lead to fullinformation rational prices are less acute, so the propensity for psychological biases may be greater. To analyse the influence of financial liberalisation, we first eliminate from our sample the 137 trading days between 18 July 1984 and 28 February 1985 that represent the bulk of NZ's financial market reform period. ${ }^{8}$ We then split our sample into a prederegulation period (prior to 18 July 1984) and a post-deregulation period (after 28 February 1985) and repeat the Table 1 calculations for these sub-samples.

Table 2 contains the results of this procedure. In general, the relationship between stock price changes and our economically-neutral events is largely independent of financial liberalisation insofar as the difference between event day returns and non-event day returns is insignificant in both sub-periods. The one notable exception to this again concerns the preholiday event. For this event, the difference in mean returns is statistically insignificant at conventional levels during the post-deregulation period, but is significant at the $2 \%$ level during the earlier period. This occurs despite the point estimate of the difference being higher in the later period (18 percentage points versus 14 percentage points), thus reflecting the lower volatility of returns prior to liberalisation. ${ }^{9}$

$7 \quad \$ 100$ invested on 11 January 1967 would have grown to $\$ 355.75$ by the end of the 8603 day period while the pre-holiday-only strategy would have seen the \$100 grow to \$122.12 from 123 days invested. Again, because we use a capital index, this calculation ignores dividends. Including dividends would reduce the magnitude of this phenomenon, but not eliminate it.

8 For a chronology of these reforms, see Margaritis et al (1992).

9 For example, the standard deviation of daily returns for non-event days during the pre-deregulation period is $0.59 \%$, but is $1.08 \%$ for the post-deregulation period. 
Table 2

\section{Comparison of event day returns with returns on all other days: Sub-samples}

This table compares the distribution of NZSE40 returns on days corresponding to the economically-neutral events listed below with returns on days that contain none of these events for two sub-periods: pre-deregulation of the NZ financial sector (1 January 1967 to 17 July 1984) and post-deregulation (1 March 1985 to 30 November 2001). Daylight savings changes occur in March and October of each year since 1974. The pre-holiday event is the last trading day preceding the holidays at Waitangi Day, Easter, Anzac Day, Queen's Birthday and Labour Day. The Melbourne Cup is held on the first Tuesday of each November. The sample consists of 3977 non-event days during the former period and 3924 during the latter; the number of event days associated with each event appears below. The p-values are calculated as follows: means - t-test; proportions of positive returns - z-test; medians - Mann-Whitney U-test.

Panel A Panel B

Panel C

Mean daily returns

positive-
Proportion of

return days

\begin{tabular}{lcllc} 
Event & Non-Event & Difference & Event & Non-Event \\
Day & Day & p-value & Day & Day \\
\hline
\end{tabular}

$\begin{array}{llcllll}\text { Event } & \text { Event } & \text { Non-Event } & \text { Difference } & \text { Event } & \text { Non-Event } & \text { Difference } \\ & \text { Day } & \text { Day } & \text { p-value } & \text { Day } & \text { Day } & \text { p-value }\end{array}$

Daylight Savings (20 event days during the pre-deregulation period and 34 during the post-deregulation period)

$\begin{array}{lllllll}\text { Pre-deregulation } & -0.01 & 0.04 & 0.64 & 0.65 & 0.53 & 0.27 \\ \text { Post-deregulation } & -0.37 & 0.01 & 0.30 & 0.44 & 0.52 & 0.37\end{array}$

Pre-Holiday (64 event days during the pre-deregulation period and 58 during the postderegulation period)

$\begin{array}{lllllll}\text { Pre-deregulation } & 0.18 & 0.04 & 0.02 & 0.66 & 0.53 & 0.04 \\ \text { Post-deregulation } & 0.19 & 0.01 & 0.27 & 0.64 & 0.52 & 0.07\end{array}$

Melbourne Cup (17 event days during the pre-deregulation period and 17 during the post-deregulation period)
Pre-deregulation
0.08
0.04
0.72
0.59
0.53
0.61
Post-deregulation
0.08
0.01
0.86
0.59
0.52
0.56

Full Moon (144 event days during the pre-deregulation period and 139 during the post-deregulation period)
Pre-deregulation
0.13
0.04
0.12
0.55
0.53
0.60
Post-deregulation
0.05
0.01
0.67
0.52
0.52
0.99

Friday 13th (30 event days during the pre-deregulation period and 27 during the postderegulation period)

$\begin{array}{lllllll}\text { Pre-deregulation } & 0.04 & 0.04 & 0.99 & 0.47 & 0.53 & 0.51 \\ \text { Post-deregulation } & 0.03 & 0.01 & 0.92 & 0.56 & 0.52 & 0.69\end{array}$


Table 2 also reveals some other interesting phenomena. First, daily mean returns for the day after daylight savings changes are 30 times more negative in the post-deregulation period. Second, for all other events, the p-values are generally smaller in the pre-deregulation period, consistent with the view that behavioural tendencies have more scope in a regulated market. Third, the results suggest a significant contrast with some US findings of Fama and French (2001) who document a virtual disappearance of dividends from stock returns over the last 20 years. By contrast, our evidence that mean daily price changes have fallen from $0.040 \%$ during the pre-deregulation period to $0.013 \%$ during the post-deregulation period suggests that dividends have become a more important component of returns in NZ. Although well beyond the scope of this paper, identifying and analysing the reasons for this difference would be an interesting path for future research.

\subsection{Other tests}

Our results thus far are at best suggestive of psychological biases in the NZ stockmarket. Although our economically-neutral events are frequently associated with economically significant price changes, only the pre-holiday effect response is statistically significant. One possible reason for this is that our simple tests are mis-specified, thereby masking the true extent of the biases.

The tests of the previous section assume that the underlying returns distributions are normally distributed, but this may not be the case. To allow for this possibility, we calculate event and non-event day medians and test for differences using the non-parametric MannWhitney U-statistic. We report these results in Panel C of Tables 1 and 2. Overall, they confirm the results of the parametric tests, with the sole exception that the pre-holiday event return becomes significantly different at the $2 \%$ level from non-event day returns during the post-deregulation period. It thus seems unlikely that our results can be attributed to nonnormal data. 
A second possibility is that our price index does not fully reflect market responses to economically-neutral events. This could be the case for two reasons. First, the NZSE40 index is made up of the largest stocks in the NZ market. These are likely to be the most analysed and therefore less prone to behavioural effects; a more broad-based index containing smaller stocks may be more susceptible to such effects. Second, as mentioned earlier, the NZSE40 excludes dividends. While this should be immaterial for daily price changes, the cumulative effect over a long time series may be significant. We therefore repeat our analysis using the more extensive, and dividend-inclusive, All Ordinaries Index, available from July 1986. ${ }^{10}$ We do not report the results from this exercise as they are virtually identical to those obtained using the NZSE40 index; although economically large, the differences between event and non-event day returns approach statistical significance only for the pre-holiday event. Thus, the choice of price index does not appear to be the source of our findings.

A further possibility is that our definition of a non-event day may be too broad if, for example, seasonalities are present in the data. As these would introduce excessive noise into the comparison with event day returns, we therefore use some finer categories of non-event days for the events where this is possible. Specifically, daylight savings returns are compared with those from all other Mondays (as in Kamstra et al , 2000), Friday 13th returns with those from all other Fridays, and Melbourne Cup returns with those from other November Tuesdays. In addition, we follow the suggestion of Yuan et al (2001) and extend the full moon event period to include the seven days either side of the full moon day. ${ }^{11}$ However, none of these alternative categorisations has any qualitative effect on our results, so again we do not report them. ${ }^{12}$

The univariate tests used so far run the risk of omitted variable problems. One way to counter this is to employ a simple regression model of the kind developed by Chen et al (1986). However, Boyle and Walter (2002) report that the variables identified by Chen et al do not have any explanatory power for NZ stock returns; instead they find that the only variable with such power is the United States (US) stock market return. In Table 3, we

\footnotetext{
10 The All Ordinaries is a value-weighted gross index incorporating all listed firms.

11 This also helps reduce the problem of full moons occuring on non-trading days.

12 All unreported results are available from the authors.
} 
therefore regress daily NZ stock returns on the previous day's US return and five dummy variables corresponding to the five economically-neutral events. ${ }^{13}$ The p-values of all tests in this table are corrected for serial correlation and heteroskedasticity by computing standard errors based on the Newey and West (1987) adjustment.

\section{Table 3}

\section{Regression results}

This table estimates regression models of the relationship between daily NZ stock market returns and economically-neutral events between 1 January 1967 and 30 November 2001 inclusive. The NZ returns are on the NZSE40 index and the US returns are on the CRSP value-weighted capital index. The pre-deregulation period runs from 1 January 1967 to 17 July 1984; the post-deregulation period from 1 March 1985 to 30 November 2001. The dummy variables are set equal to 1 if the corresponding event occurs and 0 otherwise. Numbers in parentheses are p-values based on Newey-West standard errors.

\begin{tabular}{|c|c|c|c|c|}
\hline Variable & Full Period & $\begin{array}{l}\text { Pre-der } \\
\text { Period }\end{array}$ & regulation & $\begin{array}{l}\text { Post-deregulation } \\
\text { Period }\end{array}$ \\
\hline Intercept & $\begin{array}{l}0.0002 \\
(0.24)\end{array}$ & $\begin{array}{l}0.0004 \\
(0.04)\end{array}$ & -0.0001 & $(0.88)$ \\
\hline US market return & $\begin{array}{l}0.2924 \\
(0.01)\end{array}$ & $\begin{array}{l}0.0362 \\
(0.01)\end{array}$ & 0.4728 & $(0.01)$ \\
\hline Daylight savings dummy & $\begin{array}{l}-0.0019 \\
(0.25)\end{array}$ & $\begin{array}{l}-0.0005 \\
(0.61)\end{array}$ & & $\begin{array}{l}-0.0026 \\
(0.23)\end{array}$ \\
\hline Pre-holiday dummy & $\begin{array}{l}0.0012 \\
(0.11)\end{array}$ & $\begin{array}{l}0.0013 \\
(0.04)\end{array}$ & 0.0010 & $(0.39)$ \\
\hline Melbourne Cup dummy & $\begin{array}{l}0.0004 \\
(0.84)\end{array}$ & $\begin{array}{l}0.0004 \\
(0.69)\end{array}$ & -0.0010 & $(0.76)$ \\
\hline Full moon dummy & $\begin{array}{l}0.0009 \\
(0.12)\end{array}$ & $\begin{array}{l}0.0009 \\
(0.12)\end{array}$ & 0.0004 & $(0.72)$ \\
\hline Friday 13th dummy & $\begin{array}{l}0.0001 \\
(0.91)\end{array}$ & $\begin{array}{l}0.0001 \\
(0.97)\end{array}$ & -0.0007 & $(0.65)$ \\
\hline Adjusted $\mathrm{R}^{2}$ & 0.09 & 0.01 & & 0.18 \\
\hline
\end{tabular}

13 Alternatively, we could use the return on a world stock price index such as those available from Morgan Stanley or Datastream. However, neither of these indexes goes as far back as 1967, so their use would necessitate sacrificing observations, further reducing the power of our tests to detect psychological biases. Moreover, the proximity of US market closing to the opening of the NZ market means that the influence of non-US offshore markets should in any event be incorporated in the US return. 
For the full period, the only statistically significant variable is the US market return. Once the variation in NZ stock returns due to this variable is accounted for, none of the event days has any significant explanatory power, although the economic significance of some is again quite large. The sub-period results are similar: (i) most of the explained movement in NZ stock returns is due to the US stock market, particularly in the post-deregulation period; (ii) although there is evidence of a significant pre-holiday effect in the pre-deregulation period, none of the events can explain stock price changes in the post-deregulation period. While it is difficult to draw any firm conclusions from these regression models, our view is that they offer results that are essentially the same as those of the univariate tests: the relationship between mean NZ stock market returns and economically-neutral events is sometimes economically significant, but not statistically significant.

All of the above tests examine the relationship between economically-neutral events and the location of the returns distribution. Although there is, to the best of our knowledge, no psychology research that could be viewed as linking any of these events to the volatility of the returns distribution, such a link seems at least intuitively plausible. For example, changes in mood associated with each of these events may affect investor sensitivity to given changes in market conditions and sentiment; that is, investors respond more positively to good economic news (and more negatively to bad economic news) on event days than on non-event days.

To investigate this possibility, we compare the variance of returns on event days with that on non-event days. As can be seen in Table 4, return volatility is significantly greater following daylight savings changes and on full moon and Melbourne Cup days than it is on non-event days. For the daylight savings event in particular, the difference is economically large, with the standard deviation of returns on those days being approximately twice that on 
non-event days. ${ }^{14}$ These results are consistent with the view that psychological biases exert an indirect influence on the NZ stockmarket by inducing investor over-reaction to changes in economic fundamentals.

\section{Table 4}

\section{Return volatilities}

This table compares the volatility of NZSE40 returns on event days with the volatility of returns on non-event days. Data are for the period between 1 January 1967 and 30 November 2001. Daylight savings changes occur in March and October of each year since 1974. The pre-holiday event is the last trading day preceding the holidays at Waitangi Day, Easter, Anzac Day, Queen's Birthday and Labour Day. The Melbourne Cup is held on the first Tuesday of each November.

\section{Panel A: Unconditional Variance}

The sample standard deviation of returns on non-event days of $0.88 \%$ is compared with the standard deviation of returns on each of the event days listed below. The sample consists of 8045 non-event days; the number of event days associated with each event appears below. The p-values are based on an F-test for equality of variances.

\section{Standard deviation of daily returns}

(\%)

\begin{tabular}{llcc} 
Event & $\mathrm{n}$ & Event Day & $\begin{array}{c}\text { Difference } \\
\text { p-value }\end{array}$ \\
\hline Daylight savings & 55 & 1.70 & 0.01 \\
Pre-holiday & 123 & 0.89 & 0.36 \\
Melbourne Cup & 35 & 1.07 & 0.04 \\
Full moon & 288 & 0.97 & 0.01 \\
Friday 13th & 57 & 0.75 & 0.07
\end{tabular}

The model is

\section{Panel B: Conditional Variance}

$$
\left.\begin{array}{c}
\mathrm{R}_{\mathrm{t}}=\mathrm{a}_{0}+\mathrm{a}_{1} \mathrm{R}_{\mathrm{t}-1}+\mathrm{e}_{\mathrm{t}} \\
\mathrm{h}_{\mathrm{t}}=\mathrm{b}_{0}+\mathrm{b}_{1} \mathrm{~h}_{\mathrm{t}-1}+\mathrm{b}_{2} \mathrm{e}_{\mathrm{t}-1}^{2}+\sum_{\mathrm{i}=1}^{5} \gamma_{\mathrm{i}} \mathrm{D}_{\mathrm{i}} \mathrm{e}_{\mathrm{t}-1}^{2}
\end{array}\right\}
$$

$\mathrm{R}_{\mathrm{t}}$ is the stock market return at date $\mathrm{t}$; $\mathrm{h}_{\mathrm{t}}$ is the conditional variance of the date $\mathrm{t}$ stock return innovation; $D_{i}=1$ if event $i$ occurs on date $t-1$ and 0 otherwise.

14 We obtained similar results for the sub-periods, and also for the alternative categorisations of non-event 
Estimates of $\gamma_{i}$

Event $\quad \mathrm{n} \quad$ Coefficient $\quad$ p-value

\begin{tabular}{lccc} 
Daylight savings & 55 & 0.07 & 0.63 \\
Pre-holiday & 123 & -0.02 & 0.69 \\
Melbourne Cup & 35 & 0.75 & 0.01 \\
Full moon & 288 & 0.20 & 0.01 \\
Friday 13th & 57 & 0.06 & 0.48 \\
\hline
\end{tabular}

Before leaving this issue, it is important to note that these volatility tests are based on a comparison of unconditional variances. However, a standard feature of capital market return data is that large returns (of either sign) are frequently followed by further large returns (of either sign). That is, the volatility of stock returns is effectively serially correlated, resulting in a returns distribution that has fatter tails than a normal distribution. In these circumstances, a more appropriate measure of volatility is the conditional variance of returns, which can be estimated using the GARCH class of models first suggested by Bollerslev $(1986) .^{15}$

Because we wish to relate the conditional variance of returns to our economicallyneutral events, we augment the standard GARCH model with additional explanatory variables corresponding to these events; for an example of a similar approach, see Glosten et al (1993). Specifically, we estimate the following model

$$
\left.\begin{array}{c}
\mathrm{R}_{\mathrm{t}}=\mathrm{a}_{0}+\mathrm{a}_{1} \mathrm{R}_{\mathrm{t}-1}+\mathrm{e}_{\mathrm{t}} \\
\mathrm{h}_{\mathrm{t}}=\mathrm{b}_{0}+\mathrm{b}_{1} \mathrm{~h}_{\mathrm{t}-1}+\mathrm{b}_{2} \mathrm{e}_{\mathrm{t}-1}^{2}+\sum_{\mathrm{i}=1}^{5} \gamma_{\mathrm{i}} \mathrm{D}_{\mathrm{i}} \mathrm{e}_{\mathrm{t}-1}^{2}
\end{array}\right\}
$$


where:

$$
\begin{aligned}
& R_{t}=\text { stock market return at date } t \\
& h_{t}=\text { the conditional variance of the date } t \text { stock return innovation } \\
& D_{i}=1 \text { if event } i \text { occurs on date } t-1,0 \text { otherwise }
\end{aligned}
$$

The first equation in (1) includes a lagged return to account for the conditional mean autocorrelation feature of stock return indices. The second equation relates conditional variance to a persistence term and a one-lag return innovation. The effect of the latter is allowed to vary across event and non-event dates, so $\gamma_{\mathrm{i}}$ measures the incremental impact of event i on volatility.

The results from estimating model (1) appear in panel B of Table $4{ }^{16}$ With the exception of the pre-holiday period, all events are associated with higher conditional variance of returns. Of these, the increases associated with the Melbourne Cup and the full moon are significant at conventional levels. Relative to the unconditional variance comparisons, the increase in volatility is greater for Melbourne Cup day, smaller for daylight savings changes, and broadly similar for the other events. Overall, these results provide further evidence that at least some economically-neutral events result in greater return volatility. ${ }^{17}$

\section{Conclusion}

The principal results of this paper can be summarised as follows. Of the five economically-neutral events considered, only the pre-holiday period has stockmarket returns that are statistically different from those on non-event days, and even this disappears in the post-1984 period. However, several events have mean returns that differ from the mean returns on non-event days in an economically significant manner, but these effects are

16 To conserve space and focus on the issues of interest, we report only the $\gamma_{i}$ coefficients from estimation of model (1).

17 As is common in studies of stock return volatility (see, for example, Campbell and Hentschel, 1992; and Glosten et al, 1994), the volatility effect is sometimes asymmetric. That is, for some events, negative-return days are associated with higher conditional volatility while positive-return days see a fall in conditional volatility. In unreported results, we find that the absolute value of the change in conditional volatility is significant at the 0.01 level for both positive and negative pre-holiday returns, but that the results in Table 4 are otherwise unaffected. 
swamped by the noise in daily return data. Moreover, some events have return variances that significantly differ from the variances associated with non-event days. Finally, with the exception of the pre-holiday event, the event day effects are largely independent of the mid1980s market reforms.

In terms of the implications of these results for the efficient versus behavioural markets debate, both sides will find evidence to bolster their position, so an unbiased reader (if one exists) must make the judgement as to which case is more persuasive. Efficient markets supporters can point to the general lack of statistical evidence for any systematic relationship between stock price changes and the various economically-neutral events, regardless of the testing procedure employed. Behavioural proponents will be reassured by several points: the correspondence between the observed effects of economically-neutral events and those predicted by psychological or behavioural principles, the economic significance of many of these effects, the statistical significance of the pre-holiday event in some tests, and the significant difference in returns volatility associated with several events. Hopefully, future research will be able to better distinguish between these two interpretations, either by the development of more powerful testing methods or by the use of longer data series that overcome the excess-noise problem. 


\section{References}

Agrawal, A. and Tandon, K., 1994. Anomalies or illusions? Evidence from stock markets in eighteen countries. Journal of International Money and Finance, 13, 83-106.

Agus, M.D., 1973. The rejection of two explanations of belief in a lunar influence on behaviour. Unpublished masters thesis, Simon Fraser University.

Alonoso, Y., 1993. Geophysical variables and behaviour: Barometric pressure, lunar cycle and traffic accidents. Perception and Motor Skills, 77, 371-376.

Ariel, R., 1990. High stock returns before holidays: existence and evidence of possible causes. Journal of Finance, 45, 1611-1625.

Bollerslev, T., 1986. Generalized autoregressive conditional heteroskedasticity. Journal of Econometrics 31, 307-327.

Boyle, G. and Walter, B., 2002. Reflected glory and failure: International sporting success and the stock market. Applied Financial Economics, forthcoming.

Brockman, P. and Michayluk, D., 1998. The persistent holiday effect: additional evidence. Applied Economics Letters, 5, 205-209.

Byrnes, G. and Kelly, I., 1992. Crisis calls and lunar cycles: A twenty year review. Psychological Reports, 71, 779-785.

Cadsby, C. and Ratner, M., 1992. Turn-of-month and pre-holiday effects on stock returns: Some international evidence. Journal of Banking and Finance, 16, 497-509.

Campbell, J. and Hentschel, L., 1992. No news is good news: An asymmetric model of changing volatility in stock returns. Journal of Financial Economics 31, 281-318.

Chaundler, C. , 1970. Every Man's Book of Superstitions. London: A. R. Mowbray and Co.

Chen, N., Roll, R. and Ross, S., 1986, Economic forces and the stock market. Journal of Business, 59, 383-403.

Christie, M.J. and Venables, P.H. , 1973. Mood changes in relation to age, EPI scores, time and day. British Journal of Social and Clinical Psychology, 12, 61-72.

Coutts, J.A., 1999. Friday the thirteenth and the Financial Times industrial ordinary shares index 1935-94. Applied Economics Letters, 6, 35-37. 
Dichev, I. and Janes, T. , 2001. Lunar cycle effects in stock returns. University of Michigan working paper.

Durm, M., Crispin, T. and Hammonds, C., 1986. Lunar phase and acting-out behaviour. Psychological Reports, 59, 987-990.

Dyl, E.A. and Maberly, E.D., 1988. The anomaly that isn't there: a comment on Friday the Thirteenth. Journal of Finance, 43, 1286-1295.

Fama, E.F. and French, K.R., 2001. Disappearing dividends: Changing firm characteristics or lower propensity to pay. Journal of Financial Economics, 60, 3-43.

Folkard, S., Knauth, P., Monk, T. and Rutenfranz, J., 1976. The effect of memory load on the circadian variation in performance efficiency under a rapidly rotating shift system. Ergonomics, 19, 479-488.

Forgas, J. P., 1989. Mood effects on decision making strategies. Australian Journal of Psychology, 41, 197-214.

Glosten, L., R. Jagannathan, and D. Runkle, 1993. On the relation between the expected value and the volatility of the nominal excess return on stocks. Journal of Finance 48, 1779-1801.

Hicks, R., Lindseth, K. and Hawkins, J., 1983. Daylight-saving time changes increase traffic accidents. Perceptual and Motor Skills, 56, 64-66.

Hicks, R., Lawrence-Davis, J. and Guynes, S., 1980. Change in classroom deportment of school children following change from daylight saving time. Perceptual and Motor Skills, 51, 1010-102.

Hirshleifer, D. and Shumway, T., 2003. Good day sunshine: Stock returns and the weather. Journal of Finance, forthcoming.

Isen, A. M.,1989. Some ways in which affect influences cognitive processes: Implications for advertising and consumer behaviour. In A. Tybout, (ed), Cognitive and Affective Responses to Advertising. USA: Lexington Books.

Johnson, E. J., and Tversky, A., 1983. Affect, generalisation, and the perception of risk. Journal of Personality and Social Psychology, 45, 20-31. 
Kamstra, M.J., Kramer, L.A. and Levi, M.D., 2000. Losing sleep at the market: the daylight saving anomaly. American Economic Review, 90, 1005-1011.

Kitzan, L. J., 2001. Effects of induced mood on cognitive processing in healthy older and healthy younger adults. Dissertation Abstracts International: Section B: The Sciences and Engineering, 62, 2062.

Kolb, R.W. and Rodriguez, R.J., 1987. Friday the thirteenth: 'Part VII' - a note. Journal of Finance, 42, 1385-1387.

Kossoff, A., 1992. How to beat the red and green blues. Safety and Health, 146, 68-71.

Laycock, T. , 1843. On lunar influence. Lancet, ii, 438-444.

Lieber, A. and Sherin, C., 1972. Homicides and the lunar cycle: Toward a theory of lunar influence on human emotional disturbance. American Journal of Psychiatry, 129, 69-74.

Lucey, B., 2000. Friday the 13th and the philosophical basis of financial economics. Journal of Economics and Finance, 24, 294-301.

Margaritis, D., Hyslop, D. and Rae, D., 1992. Financial policy reform in New Zealand. Reserve Bank of New Zealand Discussion Paper G92/2.

Matthew, V., Lindesay, J., Shanmuganathan, N. and Eaper, V. , 1991. Attempted suicide and the lunar cycle. Psychological Reports, 68, 927-930.

Miller, N. E., 1959. Liberalisation of basic S-R concepts: Extensions to conflict behaviour, motivation and social learning. In S. Koch (ed), Psychology: A Study of Science. New York: McGraw-Hill.

Monk, T. and Alpin, L. , 1980. Spring and Autumn daylight saving time changes: Studies of adjustment in sleeping timings, mood and efficiency. Ergonomics, 23, 167-178.

Newey, W. and West, K., 1987. A simple positive-definite heteroskedasticity and autocorrelation consistent covariance matrix. Econometrica 55, 703-708.

Persson, L-O. and Sjöberg, L., 1985. Mood and positive expectations. Social Behaviour and Personality 13, 171-181.

Petengill, G., 1989. Holiday closing and security returns. Journal of Financial Research, 12, $57-67$. 
Rogers, T., Masterton, G. and McGuire, R., 1991. Parasuicide and the lunar cycle. Psychological Medecine, 21, 393-397.

Rossi, A.S. and Rossi, P.E. , 1977. Body time and social time: Mood patterns by menstrual cycle and day of the week. Social Science Research, 6, 273-308.

Rotton, J. and Kelly, F.W. , 1985. Much ado about the full moon: A meta-analysis of lunarlunacy research. Psychological Bulletin, 97, 286-306.

Sands, J.M. and Miller, L.E. , 1991. Effects of moon phase and other temporal variables on absenteeism. Psychological Reports, 69, 959-962.

Saunders, E., 1993. Stock prices and Wall St weather. American Economic Review, 83, 1337-1345.

1994. Testing the efficient market hypothesis without assumptions. Journal of Portfolio Management, 28-30.

Scanlon, T.J., Luben, R.N., Scanlon, F.L. and Singleton, N., 1993. Is Friday the 13th bad for your health? British Medical Journal, 307, 1584-1587.

Schwarz, N. and Bless, H., 1991. Happy and mindless, but sad and smart? The impact of affective states on analytic reasoning, pp 55-71, in J. Forgas, (ed), Emotion and Social Judgements. Oxford: Pergamon.

Taub, J.M. and Berger, R.J., 1976. The effects of changing the phase and duration of sleep. Journal of Experimental Psychology: Human Perception and Performance, 2, 30-41.

Templer, D., Veleber, D. and Brooner, R., 1982. Geophysical variables and behaviour: VI. Lunar phase and accident injuries: a difference between night and day. Perceptual and Motor Skills, 55, 280-282.

Yuan, K., Zheng, L. and Zhu, Q. , 2001. Are investors moonstruck? Lunar phases and stock returns. University of Michigan working paper. 